\title{
When small is better: volume reduction in severe emphysema
}

\author{
Erik Folch ${ }^{1}$ and Gunnar Hillerdal ${ }^{2}$
}

Affiliations: 'Division of Thoracic Surgery and Interventional Pulmonology, Beth Israel Deaconess Medical Center, Harvard Medical School, Boston, MA, USA. ${ }^{2}$ Karolinska Hospital Lung Clinic, Stockholm, Sweden.

Correspondence: Erik Folch, Beth Israel Deaconess Medical Center, Harvard Medical School, Division of Thoracic Surgery and Interventional Pulmonology, 185 Pilgrim Rd, Deaconess 201, Boston, MA 02215, USA. E-mail: efolchabidmc.harvard.edu

0 $@$ ERSpublications

What are our options for lung volume reduction treatment in patients with severe emphysema? http://ow.ly/PgQLV

Severe emphysema radically diminishes quality of life. The disease is a result of destruction of lung parenchyma and is most commonly associated with cigarette smoke exposure or the congenital absence of $\alpha_{1}$-antitrypsin. The elastic fibres of the lung, which in a healthy state strive to retract the lungs, are particularly affected. The inward force determined by these fibres is balanced by the chest wall, which strives to push outwards. The result is a finely balanced system where only minimal work is needed in quiet breathing. Emphysema results in a loss of elasticity of the lungs, and thus the inward traction, while the outward force of the thorax remains unopposed, resulting in lung hyperinflation. Further, the small airways, that in normal lungs are kept open and wide by the elastic recoil from the lung parenchyma [1, 2], will have predilection for collapse due to the diminished elasticity of emphysema. Thus, even mild exertion may result in dynamic hyperinflation with air trapping adding to the increased work of breathing. In the 1950s it was shown that removal of emphysematous regions of the lung could considerably enhance lung function and quality of life by improving the total elasticity of the lungs [1]. If successful, residual volume is diminished, small airways collapse is reduced, and the chest will be less hyperinflated allowing the respiratory muscles to work more efficiently.

Surgical lung volume reduction was extensively studied and its efficacy proven around the millennium shift [3]. It is now rarely performed, probably due to a high incidence of serious and even life-threatening complications. These factors have led to a search for less invasive methods that may potentially achieve the same benefits as surgical lung volume reduction. These methods include installation of endobronchial valves [4-6] or lung sealant $[7,8]$ into affected lobes, thermal vapour ablation of selected lobes $[9,10]$ or "coiling" of the worst affected lung regions [11, 12]. For valves to be effective, a whole lobe should be targeted, and there must be no collateral ventilation with other lobes $[13,14]$. The aim is to induce atelectasis of the lobe. Severe complications are rare, but acute pneumothorax and repeated infections are well-documented. One advantage is the reversibility: the valves are easily removed bronchoscopically. Larger studies have shown statistically significant differences, but have failed to show clinically meaningful differences. However, in subgroups with high heterogeneity and complete fissures [4-6], and some small series $[15,16]$, the results have been quite good. It is also a well-established method for treating pleuro-pulmonary fistulas [17]. Coiling is used, especially in Germany, and is promising; however, we still await a cost/benefit analysis on a larger multicentre trial. This method is in practice irreversible but is independent of collateral ventilation.

In this issue of the European Respiratory Journal, Come et al. [18] report the results of a large multicentre study of volume reduction with lung sealant. The study was terminated early because of financial problems; the data monitoring committee did not recommend termination. The high incidence of severe

Received: April 272015 | Accepted: April 272015

Conflict of interest: Disclosures can be found alongside the online version of this article at erj.ersjournals.com

Copyright $\odot$ ERS 2015 
complications, including two deaths, conceivably affected the sponsor's willingness to continue financing the study. At 6 months, more than $50 \%$ of the 21 treated patients had achieved minimally clinically important differences in forced expiratory volume in $1 \mathrm{~s}$, St Georges Respiratory Questionnaire score, modified Medical Research Council dyspnoea scale score and 6-min walking test. Thus, the efficacy of the method seems to be fairly good, but the cost in side-effects is high.

One problem with the method is the extent of inflammation induced, presumably contributing to secondary infections, high rates of repeated hospitalisations in the months after the procedure, and even deaths. On one hand, a less reactive sealant might solve this problem, but on the other it is presumably the intense inflammation that causes scarification and volume reduction, resulting in improved lung function. With such a high incidence of complications, lung sealant can hardly be used in clinical practice. Thermal ablation also carries a high incidence of similar side-effects [10].

So, where are we now? The remaining less invasive methods at the moment are coiling and valves. The latter could be used in cases with a whole lobe much more damaged than the remaining one(s) or heterogeneous in the absence of collateral ventilation; unfortunately this represents only a portion of all emphysema patients. The selection of patients is crucial. A study is now starting in the UK [19] and another is ongoing in Europe, where strict selection of patients is required. These studies will hopefully definitively establish the therapeutic role for endobronchial valve placement. Coils may be used when lung destruction is not so advanced as to preclude their placement, and have the advantage of being independent of collateral ventilation. However, we need further studies on long-term follow-up and cost/ benefit analysis; one such study is now ongoing in France [20]. Surgical reduction could be considered in some cases, especially those with upper lobe predominant emphysema and poor exercise capacity [3].

Thus, since patients are different, the methods are probably not equivalent, and different approaches to different patients (especially regarding the distribution of the emphysema) are probably necessary to get the best results. More data from long-term follow-up of these therapies is needed. There are still many unknowns, but the possibility of substantially improving the life of at least some of those with severe emphysema is there, and should be pursued.

\section{The ethical questions of trial interruption}

The trial by COME et al. [18] also brings attention to a major bias in clinical research: publication bias. The authors should be commended for their integrity and resolution in publishing their findings, though incomplete. The trial was interrupted for financial reasons. Although the reader is not able to discern the specific reasons for the withdrawal of financial support, it is conceivable that it resulted from disagreements in how to conduct the trial and the large number of complications observed. Nevertheless, the publication of these findings sheds some light on the safety and effectiveness of lung sealant for the treatment of emphysema. We must recognise that for the private commercial sponsor this is a business transaction. So it is in the best interest of the researchers and institutions involved to pursue contracts that preserve academic freedom, protect the patients involved, protect the integrity of the data and bring the findings to the patients who need it most.

Investigators and industry are ethically responsible for making results publically available to influence future research endeavours. Clinical research is only justified if there is reasonable likelihood that the population in which the research is carried out stand to benefit from the results. When a trial is interrupted, the subjects who participated of the research are burdened with most of the risk and did not derive any benefits. The probability of publication of these interrupted studies is low and thus perpetuates publication bias.

Early termination of industry sponsored trials is not new and may account for more than $10 \%$ of all disputes between academic medical centres and industry sponsors [21]. However, planning during the contractual agreement may minimise the chances of this occurrence. Avoiding restrictive provisions in clinical trial agreements between academic institutions and industry is the first step towards transparency. Perhaps the second step is to implement bonds or penalty clauses for withdrawal of support.

\section{References}

1 Brantigan OC, Mueller E. Surgical treatment of pulmonary emphysema. Am Surg 1957; 23: 789-804.

2 Timmins SC, Diba C, Farrow CE, et al. The relationship between airflow obstruction, emphysema extent, and small airways function in COPD. Chest 2012; 142: 312-319.

3 National Emphysema Treatment Trial Research Group. A randomized trial comparing lung-volume-reduction surgery with medical therapy for severe emphysema. N Engl J Med 2003; 348: 2059-2073.

4 Sciurba FC, Ernst A, Herth FJF, et al. A randomized study of endobronchial valves for advanced emphysema. N Engl J Med 2010; 363: 1233-1244.

5 Venuta F, Anile M, Diso D, et al. Long-term follow-up after bronchoscopic lung reduction in patients with emphysema. Eur Respir J 2012; 39: 1084-1089. 
6 Herth FJF, Noppen M, Valipour A, et al. Efficacy predictors of lung volume reduction with Zephyr valves in a European cohort. Eur Respir J 2012; 39: 1334-1342.

7 Refaely Y, Dransfield M, Kramer MR, et al. Biologic lung volume reduction therapy for advanced homogenous emphysema. Eur Respir J 2010; 36: 20-27.

8 Magnussen H, Kramer MR, Kirsten A-M, et al. Effect of tissue integrity on lung volume reduction using a polymer sealant in advanced emphysema. Thorax 2012; 67: 302-308.

9 Snell G, Herth FJF, Hopkins P, et al. Bronchoscopic thermal vapour ablation therapy in the management of heterogenous emphysema. Eur Respir J 2012; 39: 1326-1333.

10 Gompelmann D, Eberhardt R, Herth FJF. Technology update: bronchoscopic thermal vapor ablation for managing severe emphysema. Med Deviced (Auckl) 2014; 7: 335-341.

11 Slebos DJ, Klooster K, Ernst A, et al. Bronchoscopic lung volume reduction coil treatment of patients with severe heterogenous emphysema. Chest 2012; 142: 574-582.

12 Shah PL, Zoumot Z, Singh S, et al. Endobronchial coils for the treatment of severe emphysema with hyperinflation (RESET): a randomised controlled trial. Lancet Respir Med 2013; 1: 233-240.

13 Fessler HE. Collateral ventilation, the bane of bronchoscopic lung volume reduction. Am J Respir Crit Care Med 2005; 171: 423-424

14 Herth FJF, Eberhardt R, Gompelmann D, et al. Radiologocal and clinical outcomes of using Chartis ${ }^{\mathrm{TM}}$ to plan endobronchial valve treatment. Eur Respir J 2013; 41: 302-308.

15 Hillerdal G, Mindus S. One- to four- year follow-up of endobronchial lung volume reduction in Alpha-1-antitrypsin deficiency patients: a case series. Respiration 2014; 88: 320-328

16 Hopkinson NS, Kemp SV, Toma TP, et al. Atelectasis and survival after bronchoscopic lung volume reduction for COPD. Eur Respir J 2011; 37: 1346-1351.

17 Dooms CA, Decaluwe H, Yserbyt J, et al. Bronchial valve treatment for pulmonary air leak after anatomical lung resection for cancer. Eur Respir J 2014; 43: 1142-1148.

18 Come CE, Kramer MR, Dransfield MT, et al. A randomised trial of lung sealant versus medical therapy for advanced emphysema. Eur Respir J 2015; 46: 651-662.

19 Davey C, Zoumot Z, Jordan S, et al. Bronchoscopic lung volume reduction with of endobronchial valves for patients with heterogenous emphysema and intact interlobar fissures (The BeLieVeR-HIFI trial): study design and rationale. Thorax 2015; 70: 288-290.

20 Deslee G, Barbe C, Bourdin A, et al. Cost-effectiveness of lung volume reduction coil treatment in emphysema. STIC REVOLENS. Rev Mal Respir 2012; 29: 1157-1164.

21 Mello MM, Phil M, Clarridge BR, et al. Academic Medical Centers' Standards for Clinical-Trial Agreements with Industry. N Engl J Med 2005; 352: 2202-2210. 